EPiC Series in Computing
Volume 52, 2018, Pages 398-409
$\begin{aligned} & \text { ICT4S2018. 5th International Conference on Informa- } \\ & \text { tion and Communication Technology for Sustainability }\end{aligned}$

\title{
Transparent Farmers: how CSA farmers are using technology for new ways of selling and communicating with consumers
}

\author{
Jorge Luis Zapico ${ }^{1,2}$ and Maja Söderberg ${ }^{1}$ \\ ${ }^{1}$ Nybrukarna, Tolg, Sweden \\ ${ }^{2}$ Linnaeus University, Växjö, Sweden \\ \{jorge, maja\}@nybrukarna.se
}

\begin{abstract}
There is a growing number of farmers embracing information and communication technologies (ICT) as a way of enabling direct sales to consumers and creating added value through involving the consumers and making food production more transparent. This article presents the case of Nybrukarna, a community supported agriculture (CSA) cooperative in the south of Sweden, and explores how social media is used in their operation. The social media posts during a growing season were analyzed and used to identify different cases. Three main themes were identified: (1) practical communication and feedback from customers; (2) increasing transparency of crop production and values; (3) marketing and direct sales. These results were combined with information from a survey with feedback of the CSA customers, and a survey with growers in similar context, for identifying and discussing challenges, drivers, and opportunities for future development and research.
\end{abstract}

\section{Introduction}

There are a growing number of farmers embracing information and communication technologies as a way of enabling direct sales to consumers and creating added value through involving the consumers and making food production more transparent. Profitability is a major challenge for farmers globally. In a commodity market, farmers get only a decreasing portion of the value, with most profit staying with resellers and supermarkets (European Commission, 2009). One strategy for farmers is to sell their products directly to consumers to keep a bigger share of the value and market their produce in a more individualized way. Community Supported Agriculture (CSA) is a directsales model where consumers share the risks and benefits of production. CSAs can either be "subscription CSA" in which one or more farmers drive the organization and farm work is not required of subscribers (even if participation is promoted), or "shareholder CSA" which is subscriber 
driven and distribute work between members and/or hire a farmer to take care of production (Adam, 2006). The CSA model creates a security for the farmers, as sales are guaranteed from the beginning of the season and production can be planed in advanced accordingly. The consumers share some of the risks of production, for example if a certain crop yields poorly due to bad weather, the consumers will get less of it, but as CSAs are based on diversified farming it will probably be balanced with other crops that did better. The farmers benefit also from having a guaranteed sale of the produce, without the risks for example of going to a farmers market on a rainy day and having to take back unsold produce.

While CSAs have been and can be run without the help of technology, many CSAs are embracing ICT and social media for the possibilities of direct marketing and communication. Information and communication technologies are empowering these initiatives and providing opportunities for new producer-consumer systems and shorter supply chains. Some of these focus on increasing the visibility of producers to create new connections between consumers and producers*, while others focus on simplifying the administration and marketing of the producers ${ }^{\dagger}$. This work can be situated in the ongoing research in ICT4S and sustainable HCI around how ICT could be used for increasing the sustainability of food production and consumption (Blevis and Morse, 2009; Svenfelt and Zapico, 2016; Norton et al., 2017).

This article presents the case of Nybrukarna, a subscription CSA cooperative in the south of Sweden of which the authors are part. Nybrukarna started in 2014 and has grown to provide weekly vegetable deliveries to 70 subscribers plus wholesale to restaurants and central kitchens. At Nybrukarna we have worked with leveraging social media for communicating with our subscribers, and as our main marketing tool. In 2017 we worked more intentionally with social media in an effort to make our production more transparent. This article analyses the results from this effort by combining the data from:

- $\quad$ Social media usage during the growing season (March 2017 to October 2017).

- A survey with feedback from our customers from the previous season (2016).

- A survey with growers in similar situations.

Based on these results, the article will explore the following questions:

1. How was social media used in practice and what are the lessons learnt?

2. What are the drivers and barriers for social media use?

3. What are the risks and opportunities in using social media in a CSA setting?

\section{Increasing Transparency and Participation}

At Nybrukarna we are using social media for increasing the transparency of our production, and involving and communicating with our customers. Through a questionnaire to our customers in 2016 $(n=32)$ it was identified that some of the reasons why most chose to subscribe to our CSA were connected to being more active in their food consumption by: promoting local and small farms $(93 \%$ of participants) and promoting sustainable food production (87\%). While some of our customers are close enough to the fields as to be able to follow the progress naturally, most are located in other places in the region. We use social media to provide a connection to our production, communicate our practices, and get feedback from our consumers.

\footnotetext{
${ }^{*}$ An example in Sweden is http://gardsnara.se

${ }^{\dagger}$ For example Farmigo http://farmigo.com/software
} 
We have presence in Facebook, Instagram, YouTube, Soundcloud, and a blog in our website using Wordpress. Most activity connected with our customers is concentrated in Facebook where we have a group specific for our CSA subscribers. A public Facebook page is also used for increasing visibility of our production but with focus on outreach and marketing.

From the answers from our subscribers from $2016(\mathrm{n}=32)$ we could also see that social media information was appreciated:

- $87.5 \%$ of the customers liked the information about what crops we were growing

- $62.5 \%$ liked the information about how we were growing them.

- However, more detailed knowledge about crops and techniques was valued only by $28 \%$ of our CSA members.

On these grounds we made a proactive effort during 2017 for increasing the use of social media with focus on providing our subscribers with insight about the growing season and the crops being grown. While we increased social media use, we lacked insight on how we were actually using social media in practice. In this section we explore the social media usage in Facebook during a growing season (March 2017 to October 2017), which included:

- Facebook CSA subscriber group: 138 posts, 107 by the CSA farmers and 31 by the subscribers. The group had 112 members.

- Facebook pages: 39 posts. The Facebook page had 834 followers at the beginning of the period and 980 followers at the end.

We have analyzed and organized the posts in six cases which represent our different uses of social media (some posts are counted in two categories):

- Practical communication with customers (58 posts)

- Following the growing season (63 posts)

- Getting feedback and answering questions (23 posts)

- Presenting methods, practices and values (20 posts)

- Marketing (36 posts)

- Crowdfunding (5 posts)

\footnotetext{
${ }^{\ddagger}$ https://www.facebook.com/groups/nybrukarnasandelsjordbruk/

${ }^{\S}$ https://www.facebook.com/nybrukarna
} 


\subsection{Practical communication with customers}

Most posts in the CSA subscribers Facebook group were connected to practical communication to the CSA members (49 posts), for example confirming delivery and content of the boxes each week or communicating some problem or delay. Of these 49 posts, 19 had also content connected to the crops and the growing season. Figure 1 shows a typical example of these posts, it points that the boxes have been delivered to two of the pickup points and on their way to a third one, and it has a picture of the leeks that are part of that week's share. There were also 8 posts from our subscribers with questions about the deliveries or other practicalities. Figure 2 shows an example from one of our subscribers who wanted to check the fields asks if there is need for harvesting help.

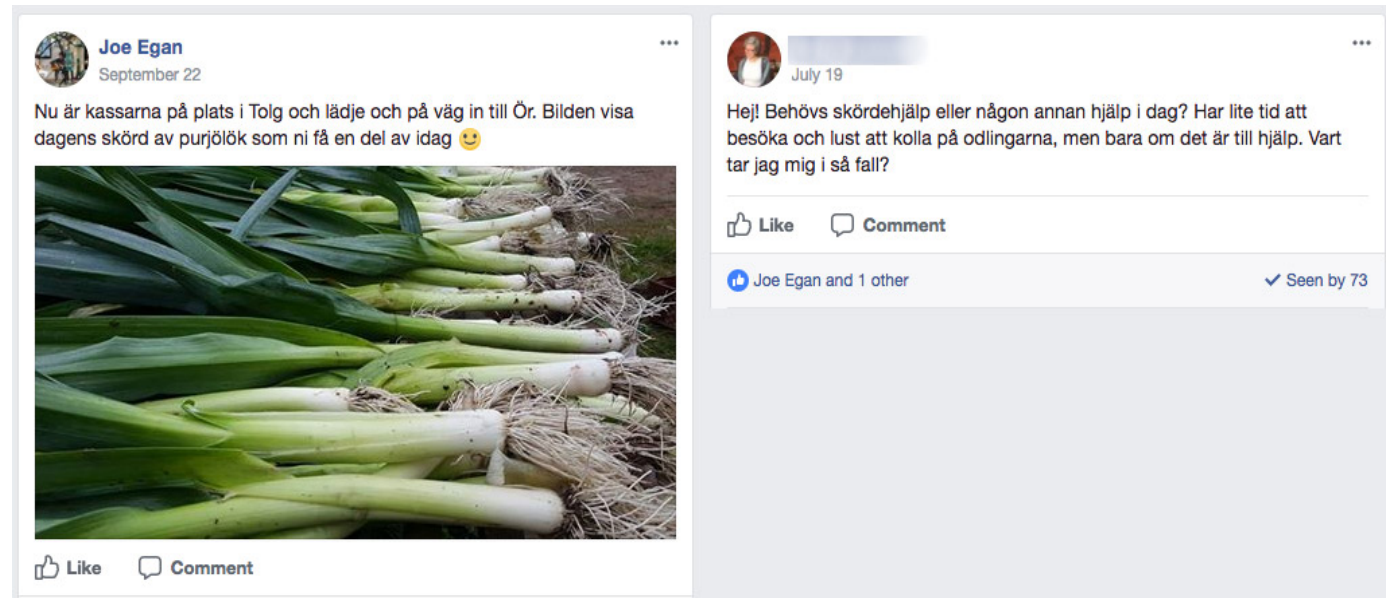

Figure 1 (left): An example of communication message: "The boxes are already in place in Tolg and Lädja and on its way to Ör. The picture shows todays leek harvest that you will get in the boxes."

Figure 2 (right): Example of question from CSA subscriber: "Hi! Do you need help today harvest or anything else? I have some time for visiting and I wanted to check up the fields, but only if it is useful. Where do you want me to go?"

\subsection{Following the growing season}

An important part of our media use is increasing the visibility of our production, and a total of 63 posts presented media and information about the crops and growing seasons. This included 32 posts in the subscribers group and 12 in the public page. Examples of such posts include: presenting when a crop is sown or transplanted, showing the development of a crop to show that it is on its way, presenting varieties or crops that are included in the deliveries, or discussing particulars of the growing season and how it affects the crops and the deliveries. These posts have for the most part media content, with 56 having a picture and 1 being a video.

An example of these posts can be seen in Figure 3, that explains different developments during spring such as that fast crops were planted in the greenhouse before it was time for tomatoes and cucumbers and that we had planted strawberry plants for the next season. This post was published in May, when our subscribers had already signed up but there were still no deliveries, so such posts were a way of communicating the "invisible" ongoing work and creating expectation for the upcoming deliveries. 


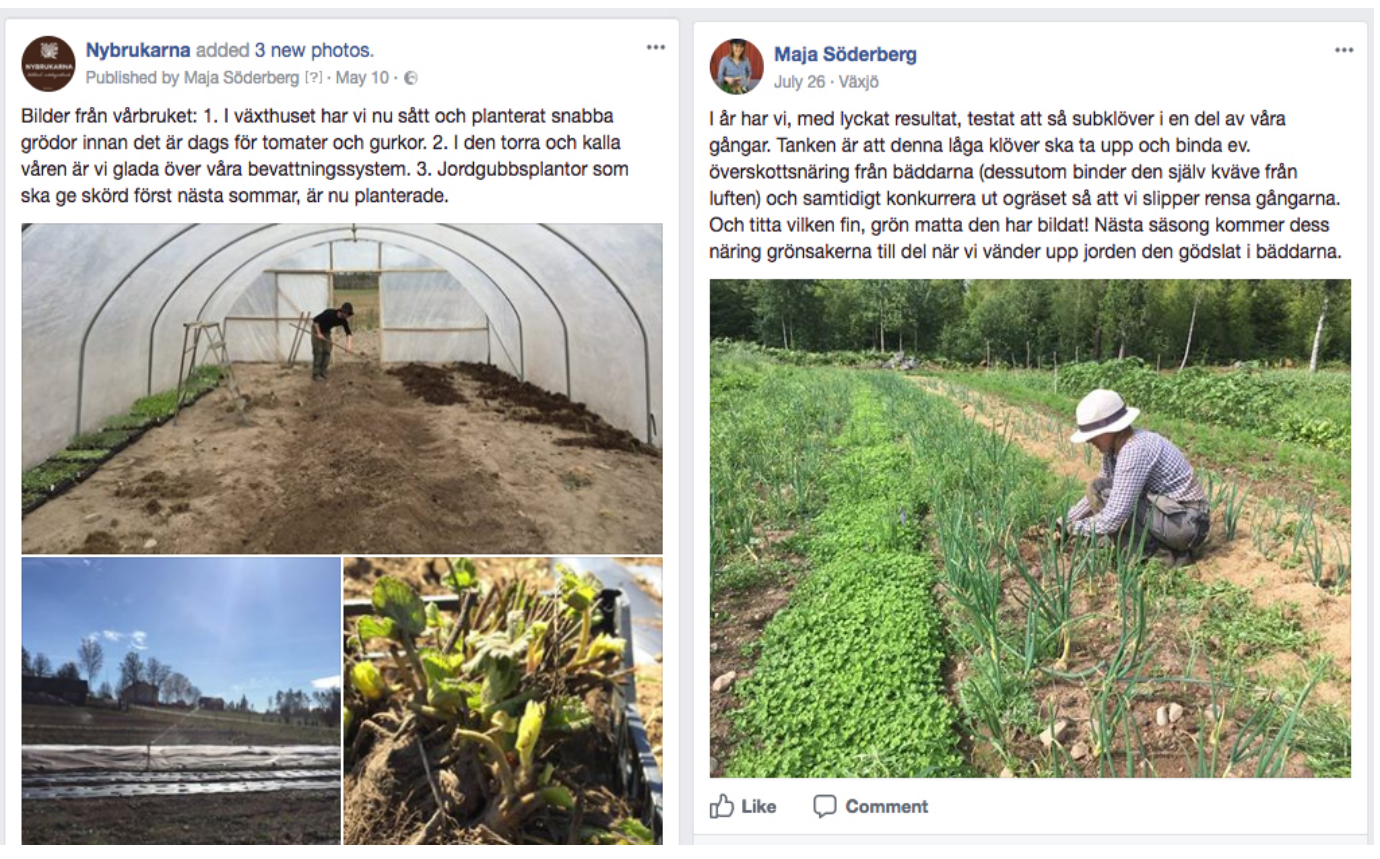

Figure 3 (left): An example of a post showing production and crop development: "Picture from spring work: 1. Inside the greenhouse have we sowed and planted fast crops to harvest before it is filled with tomatoes and cucumbers. 2. This spring is cold and dry so we are happy about our watering system 3 . We have planted strawberry plants that will give crop for next year"

Figure 4 (right): Post showing sustainable production practice: "This year have we tested with success sowing clover in the paths. The idea is that this low growing clover will bind nitrogen from the air and stop nutrients from leaching, at the same time that we do not need to weed the paths. Looking nice and lush too! Next season the nutrients collected will be put back in the soil for the vegetables."

\subsection{Getting feedback and answering questions}

An important part of using social media is being able to not only communicate with customers, but to get feedback from them. A total of 23 posts were posted by our subscribers (this does not include feedback in the form of comments on other posts). Of these 23, 17 were positive feedback and encouragement from customers, like in Figure 6: "Thanks for the awesome vegetables! The white carrots are really great" or in Figure 5, where a customer shows a dinner made with our produce.

The other 6 posts were questions about the produce, usually about what to do with a certain vegetable, which we and other customers answered to with suggestions. We have also gotten negative feedback through private message about things that have not been good or things that could be improved, which it has been valuable for us. 


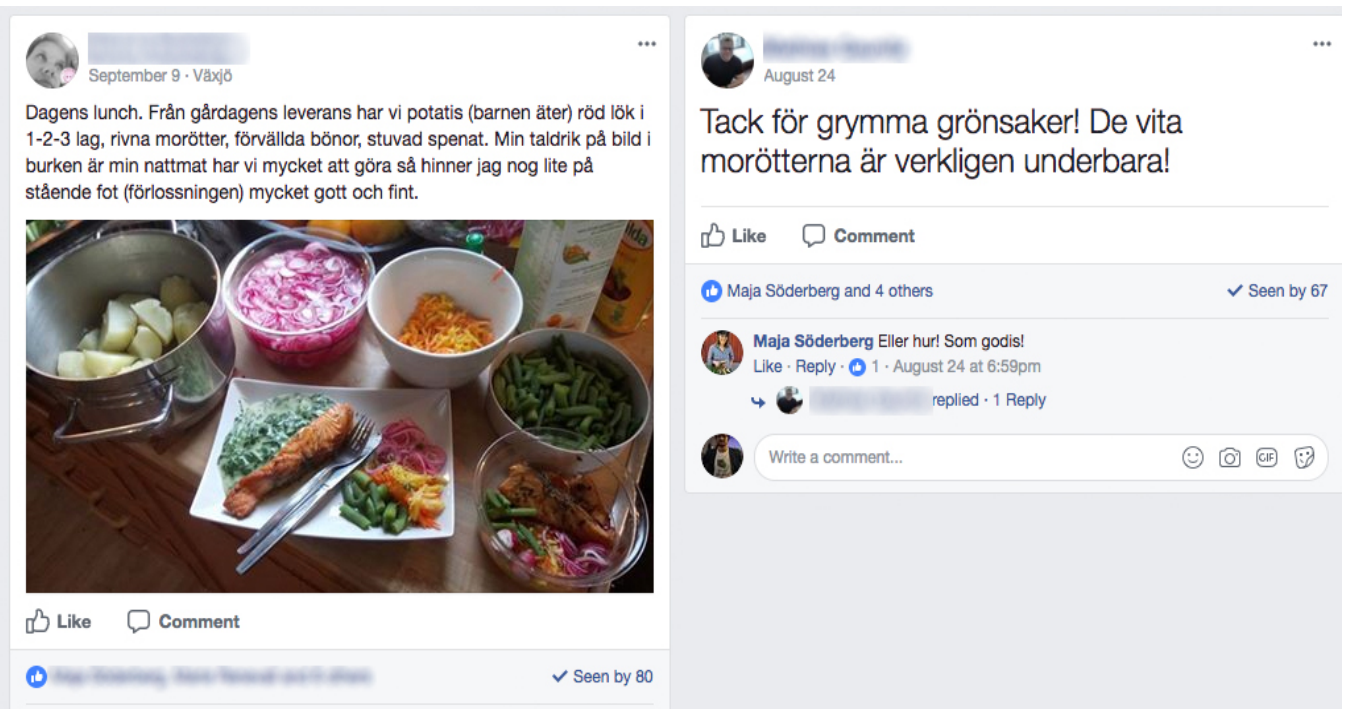

Figure 5 (left): Example of feedback from subscriber using our produce: “Today's lunch: From yesterday's delivery we have potatoes, pickled red onion, shredded carrots, beans and spinach. [...]"

Figure 6 (right): Example of positive feedback: "Thanks for the awesome vegetables! The white carrots are really great"

\subsection{Presenting methods, practices and values}

One of our key values is working with sustainable methods and practices, which as presented above is one of the reasons customers choose to be part of our CSA. We use social media to be transparent about our methods, to educate our customers about food production and to argue how we are working towards a more sustainable food production, and a total of 20 posts were connected to this. As more specific information on the techniques was not valued from our subscribers, these posts are kept short and at a more general level. An example is Figure 4 where we explain how we have planted clover in some of the footpaths and why that is good for nitrogen fixation and avoiding weeds.

Being able to communicate directly with our customers means that we can present our values and reducing food waste. One example was the delivery of potatoes with scab. While potatoes with scab are safe to eat, the cosmetic damage makes them impossible to sell, thus making this disease a large financial loss for the farmer. We could explain this to our customers to avoid the waste of that produce, writing that: "Unfortunately many of our potatoes got scab this season [...]. Peel the potatoes or remove the scab with a knife and they are as good as usual [...]", and get some feedback on the acceptance, with one of our customers writing: "They are really good in a gratin anyhow" (Figure 8).

\subsection{Marketing}

An important role of social media is in marketing, both in direct marketing for acquiring new customers and in a more general "brand" image building. Most of the posts in the public Facebook group are oriented towards this, with the group having a broader reader base. Of the 29 posts, 10 are press clips with articles about Nybrukarna or our projects, 12 are stories and pictures about the growing season, and 7 were more related to sales and attracting new customers at the beginning of the 
season. The posts had an average of 1685 views. An example in Figure 7 shows the composition of one of our weekly deliveries with assorted vegetables, in this case not for the subscribers but published in the public page to show our produce and what our CSA subscribers get. Another usage of social media is in marketing sales occasions, which as a CSA we do not do often. An example post can be seen in Figure 9, where we announce sales of our produce in a local market, with time and place and pictures of the available vegetables.

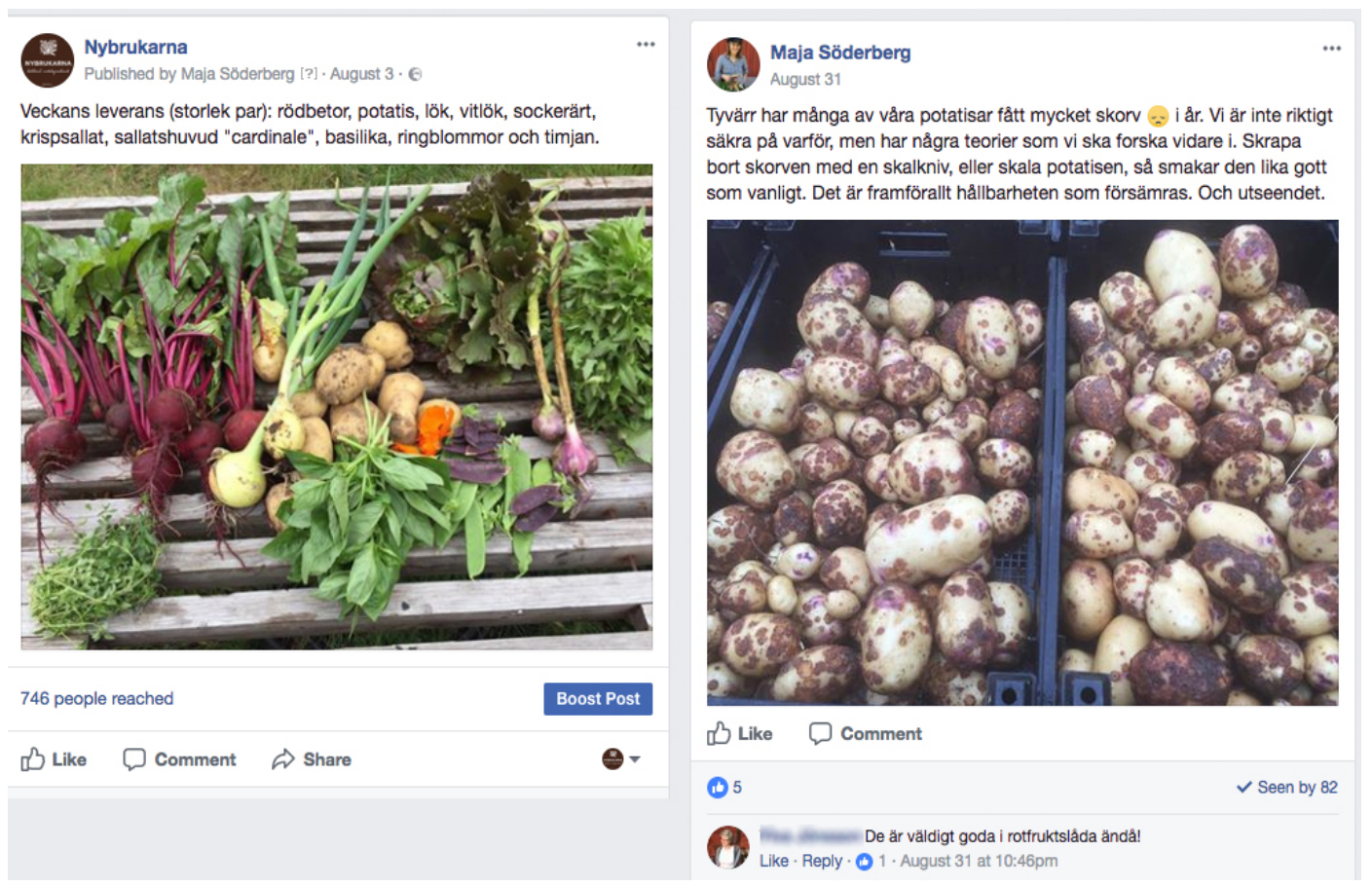

Figure 7 (left): Post showing an example of what our CSA subscribers get: "Delivery of the week (medium size): beetroots, potatoes, onions, garlic, snap peas, lettuce, basil, calendula and thyme."

Figure 6 (right): Post showing potatoes with scab: "Unfortunately many of our potatoes got scab this season. We are not sure why, but we have some theories we are exploring. Peel the potatoes or remove the scab with a knife and they are as good as usual. It is mostly the shelf life that worsens with scab. And the looks."

\subsection{Crowdfunding}

At Nybrukarna we created a successful crowdfunding campaign in the spring of 2017 for funding a new tomato greenhouse, and a total of 5 post were connected to it. The crowdfunding was run as a social media campaign, including a paid Facebook promotion that reached more than ten thousand views (See figure 10). Social media was also used to communicate the development of the crowdfunding and the resulting greenhouse purchase and building. 


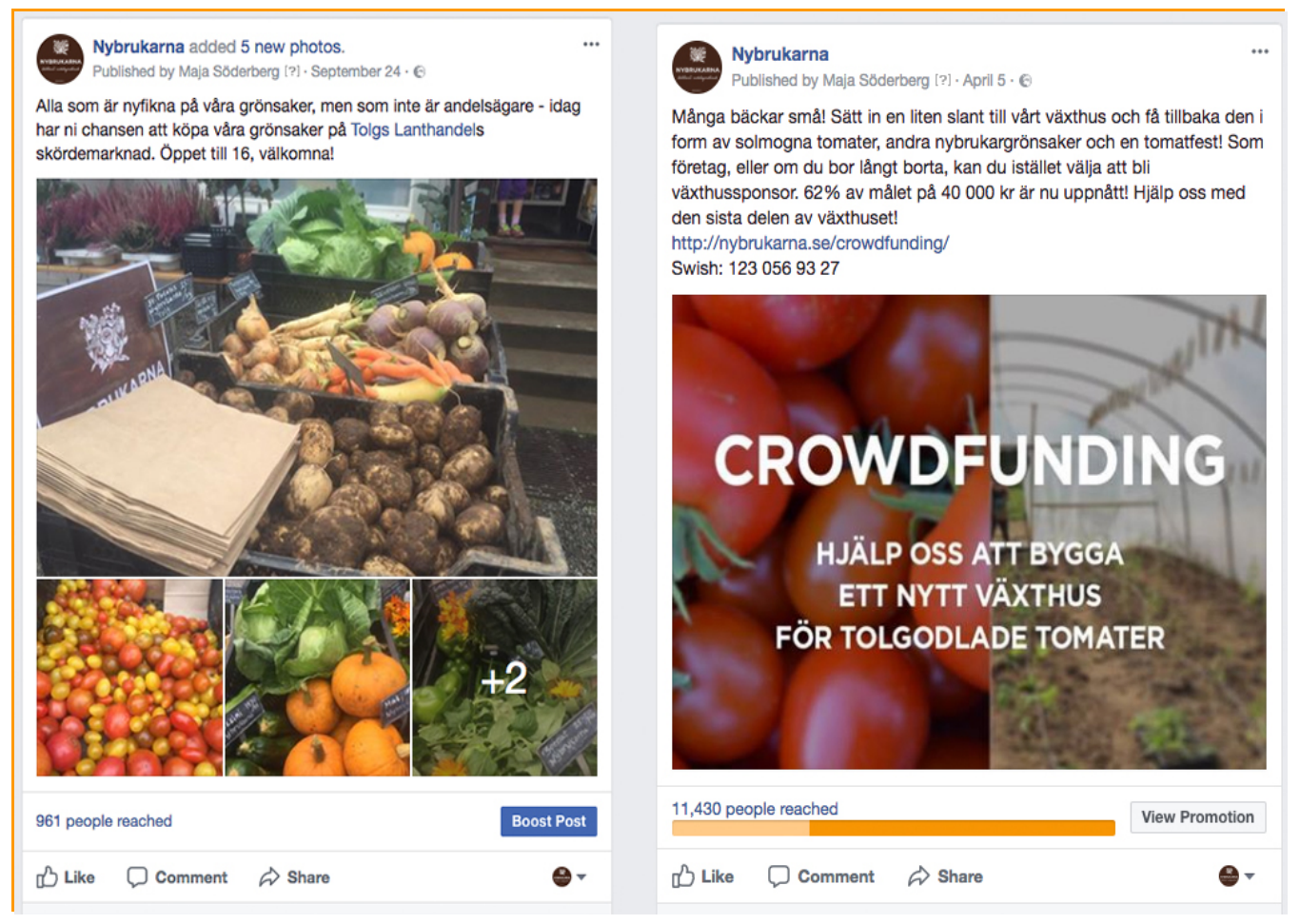

Figure 7 (left): Post announcing market sales: "For all of you who are interested in our vegetables but not part of our CSA: today you are welcome to buy our produce at Tolg's General Store. Open until 16"

Figure 8 (right): Advertisement for our greenhouse crowdfunding: "Every little helps! Contribute to our greenhouse and get back sun ripe tomatoes, other vegetables from Nybrukarna and a tomato party! If you are a company, or if you live far away, you can instead become a sponsor. We have achieved $62 \%$ of our goal of 40000 SEK! Help us with the last part of the greenhouse!"

\section{What Are Other Farmers Doing?}

As a part of our work with social media we sent out a questionnaire to get a first overview about how other farmers in similar situations are also working with technology. The questionnaire was sent through Facebook to professional groups of small farmers and 26 answers were collected during the first round:

- The participants were all vegetable farmers, of which 10 of them were running a CSA. Some participants $(n=7)$ had also other farm production such as cereals, meat, egg or honey.

- There was a distribution between part time farmers $(n=16)$ and full time farmers $(n=10)$.

- There was a good age distribution, while most were in their thirties $(\mathrm{n}=16)$, some were older $(n=7)$, younger $(n=2)$ or did not answer $(n=1)$. A majority of full time farmers were in the group older than 40 .

- All participants had a smartphone and a computer, some participants $(n=9)$ had access to fiber broadband. 
The main goal of the questionnaire was getting information about the drivers and barriers of other farmers for using social media and ICT, to be able to compare with our own experiences at Nybrukarna.

\subsection{Drivers}

Most participants used social media actively to communicate their production $(88 \%)$, while a few of them (12\%) were not very active. All of them used Facebook, followed by Instagram (52\%) and having an own website (44\%).

22 participants used social media as a tool for selling their produce, with 15 of them using social media for selling directly with consumers, 16 of them using social media for communicating sales points and availability, and 2 of them selling through an online retail. These are different goals than what we have as subscriber CSA, as mentioned before.

Most participants had multiple driving forces in their social media use: communicating easily with their customers $(96 \%)$, communicate with other producers $(88 \%)$, find new customers $(80 \%)$ and increase transparency of their production methods $(72 \%)$, which are in line with our goals at Nybrukarna.

\subsection{Barriers}

The main limitation for using social media was lack of time, mentioned by 14 participants $(78 \%$ $\mathrm{n}=18$ ). A total of 8 participants name technical limitations as a barrier, from lack of knowledge to lack of equipment. 1 participant is just not interested in using social media. When asked if using these technologies was something they enjoyed or just something they felt obligated to in a likert scale, $46 \%$ answered towards the positive end, while other $46 \%$ answered neutral, and $8 \%$ answering that it was mostly an obligation (See figure 11). The answers are also in line with our own experience. A bias towards "technology-friendly farmers" is built in as the participants were gathered through social media, but the results still shows that the drivers and barriers for using social media are not unique for our CSA but shared with other farmers in similar situations.

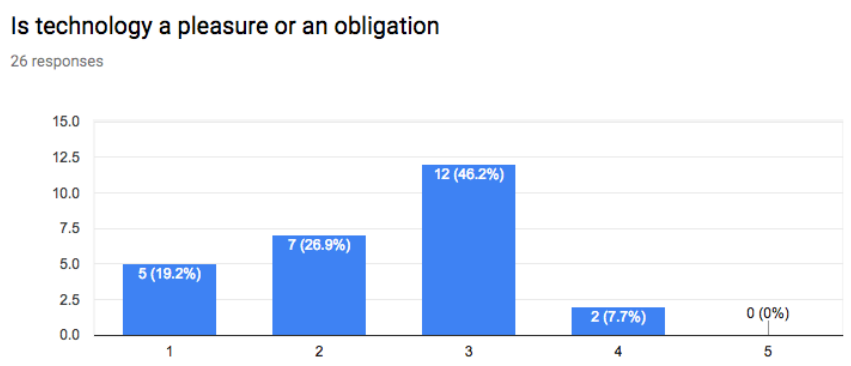

Figure 9: Responses from attitude to technology ( 1 most positive, 5 most negative)

\section{Discussion and Conclusions}

\subsection{Opportunities}

Farmers and CSAs, as ourselves at Nybrukarna, are leveraging information and communication technologies affordances for creating short supply chains with increased transparency as an added 
value. This article has looked at the actual social media use during a year and identified some opportunity areas. These can be condensed in three main topics:

Communication: Social media can streamline practical communication and feedback from customers, allowing easy communication and possibility of discussion also between customers. Examples of this usage include: communicating of deliveries both regular and in case of problems; providing customers a channel for feedback, both positive and negative; answering questions regarding crops and usage of vegetables. This direct communication provides a way to create a closer connection between producers and consumers.

Increasing transparency: Social media can be used for increasing transparency of crop production and the production methods. This includes the publication of pictures, videos and texts about: when a crop is sown or planted; the development of a certain crop; problems of some crop; techniques or tools used; when a crop is harvested. Increasing transparency through the use of media can have different goals such as:

- Increasing the feeling of participation of the consumers in the food production process.

- Educating the consumers about food production so they gain an understanding of when crops are in season, and what it takes to grow them, so they understand the limitations of local growers.

- Ensuring the consumers that the work done is in accordance to the expected values such as sustainable, small-scale, local, fair.

Marketing and direct sales: Social media can be used for marketing and finding new customers. Increasing transparency and communication of the production is also used as a marketing tool and brand building. Showcasing the values of the farm through media as discussed above can also be used for marketing purpose to attract customers that want to support local farmers and sustainable food production.

ICT can be also used for coordinating direct sales, either by using social media for communicating sales points and availability or pre-booking produce, or by selling through online retail.

\subsection{Risks}

A main risk of social media usage is that it becomes yet one more thing to do for the farmers. Time is the main limitation both in our experience and for most of the farmers asked in our study. Documenting and posting to social media may not be a priority when vegetables need to be harvested, fields weeded and plants transplanted. From the survey and our own experience we can say that media creation is seen mostly a positive activity ("showing of the beautiful things we produce") than being an obligation ("I would rather keep weeding"). But it could be argued that there is a risk if it becomes a norm that is expected of each grower/CSA instead than an extra, and so creating more work load for everyone but losing the added value.

There are also problems connected with an increased dependence on a specific social media such as Facebook. Facebook in our case has become the de-facto communication tool due to their "monopoly" on existing users. Communicating and posting media in Facebook raises some questions about ownership of the content.

Finally, as the image created in social media is selective, there could be also a risk of appropriation for using the same media language to project a false image of sustainability or smallscale in cases where it is not true, see for example the analyses of Phillipov (2016) and Heath and Meneley (2007). 


\subsection{Further work and opportunities}

There are many opportunities for further work in this topic. This article has explored one CSA's social media use, future work could look to other cases in different contexts, and to multiple CSAs and farmers in a wider study. Next step at Nybrukarna is getting feedback from the users for the communication during the 2017 season, and based on the feedback and the analysis presented in the article, create a more explicit strategy for what and when to publish.

Time pressure is a big barrier towards publishing media content. Different technical solutions could be explored towards how to tackle this. Further enquiry on the consumers' response could help also optimizing the amount of published media that is valued.

There are also topics that have not been touched in this article. One is communication between farmers. Social media is a part of the creation of a new movement of small-scale sustainable vegetable farming and CSAs, including podcasts, video channels, social media accounts, and more organized movements. Our survey showed that our customers are not that interested about in depth articles on techniques, but those can be of interest for the community of practice. Future work could explore both the role of social media in the creation of a global community of practice around sustainable smallscale agriculture, and opportunities for ICT for empowering it.

Another interesting topic is the creation of specific tools for the administration and management of CSA and market farms. This type of farming is quite management intensive, as it deals with producing a big variety of crops, staggered through time for providing a continuous flow of produce throughout the season. Direct sales also increase the management load as instead of a few wholesale operations, there are weekly deliveries to many customers, and simple things like managing pauses on delivery for a week can get fast out of hand when the number of customers grow. There are tools like Farmigo (see footnote 1) targeting this type of operation, but there is still space for innovation.

One important aspect to keep in mind in the development of tools for use by farmers is that a participatory process is necessary to increase the usefulness of the solutions and to create an ownership feeling from the farmers so the tools do get used (Pretty 1995; Cerf et al, 2012).

\subsection{Conclusions}

This article presents an analysis of how a CSA is using ICT, and specifically social media, for new ways of selling and communicating with customers. Based on data from the social media use during a growing season and the results from surveys to CSA subscribers and other growers we identified three main areas where ICT is empowering short supply chains between food producers and consumers: facilitating communication and feedback between producers and consumers; making production visible; and providing marketing and direct sales opportunities. Making food production more visible through the use of social media provides an added value to consumers who want to be more involved in their food choices and to support producers who share their values. The created content is also useful as a marketing tool for communicating production values and quality. In the context explored, time is the biggest barrier to social media usage, and there is a risk that a pressure towards more transparence and media use would create an extra workload for the farmers. There are research opportunities for the field of ICT4S and Sustainable HCI to further explore the topic of how CSAs are using technology and to compare different contexts and settings, and to explore new spaces for research and development of ICT tools for empowering community supported agriculture.

\section{Acknowledgment}

This article is a result of work financed by Jordbruksverket, the Swedish Agriculture Agency as a part of the project "Transparenta Bonden", run by Nybrukarna. 


\section{References}

Adam, K.L. (2006). Community supported agriculture. Butte, MT: ATTRA-National Sustainable Agriculture Information Service.

Blevis E. and Morse, S.C. (2009). Sustainable ours: Food, Dude. interactions 16, 58-62

Cerf, M. Jeuffroy, MH. Prost, L. (2012). Participatory design of agricultural decision support tools: taking account of the use situations. Agron. Sustain. Dev. 32: 899.

European Commission. (2009). The evolution of value-added repartition along the European food supply chain. http://ec.europa.eu/economy_finance/publications/pages/publication16075_en.pdf

Heath, D. and Meneley, A. (2007). Techne, technoscience, and the circulation of comestible commodities: An introduction. American Anthropologist 109.4 (2007): 593-602.

Norton J. et al. (2017). A grand challenge for HCI: food + sustainability. interactions 24.6: 50-55.

Phillipov, M. (2016). The new politics of food: Television and the mediaffood industries. Media International Australia 158.1: 90-98.

Svenfelt, A. and Zapico Lamela, J.L. (2016). Sustainable food systems with ICT?. The 4th International Conference ICT for Sustainability, 'Smart and Sustainable'(ICT4S 2016, Aug 29-1 Sep, 2016, Amsterdam. Atlantis Press.

Pretty, J.N (1995). Participatory learning for sustainable agriculture. World development, 23(8), 1247-1263. 